University of Wollongong

Research Online

Faculty of Law, Humanities and the Arts Papers (Archive)

$1-1-2020$

\title{
Should I use my 'weak' social capital or 'strong' guanxi? Reviewing and critiquing two theories in the context of Western-Chinese migration
}

Zhuqin Feng

University of Wollongong, zf251@uowmail.edu.au

Roger Patulny

University of Wollongong, rpatulny@uow.edu.au

Follow this and additional works at: https://ro.uow.edu.au/lhapapers

Part of the Arts and Humanities Commons, and the Law Commons

Research Online is the open access institutional repository for the University of Wollongong. For further information contact the UOW Library: research-pubs@uow.edu.au 


\title{
Should I use my 'weak' social capital or 'strong' guanxi? Reviewing and critiquing two theories in the context of Western-Chinese migration
}

\author{
Abstract \\ The Author(s) 2020. Social network dynamics are complex in the context of Chinese overseas migration \\ because of the unique dynamics of guanxi, which are distinctly different from 'Western' social capital. The \\ few migration studies comparing guanxi and social capital suggest that the former largely consists \\ 'strong ties', while the latter is comprised of 'weak ties'. However, most apply only a cursory comparison \\ of one network facet. We review core literature in the two fields to contrast what each says about network \\ norms, structures and practices. We find that: (i) guanxi is characterised by dynamics of 'face' and \\ renqing; (ii) guanxi has core and peripheral aspects that grant it bonding and bridging qualities; (iii) weak \\ ties in social capital networks are more beneficial for acquiring non-redundant resources, and for joining \\ civic/voluntary associations; (iv) while strong, face-based guanxi ties better mobilise valuable resources, \\ these ties are rarely transformed into social capital.

\section{Disciplines} \\ Arts and Humanities | Law

\section{Publication Details} \\ Feng, Z. \& Patulny, R. (2020). Should I use my 'weak' social capital or 'strong' guanxi? Reviewing and \\ critiquing two theories in the context of Western-Chinese migration. Journal of Sociology,
}




\section{Should I use my 'weak' social capital or 'strong' guanxi? Reviewing and critiquing two theories in the context of Western-Chinese migration}

\section{Author 1}

\section{Author 2}

\section{Introduction}

In recent years, there has been growing interest in the role of networks in fostering social cohesion. This is seen in the proliferation of social capital studies. Social capital is defined as "networks together with shared norms, values and understandings that facilitate cooperation within or among groups" (OECD, 2001: 41). It has various qualities emphasised to different degrees in the field. These include collective capital assets (Bourdieu, 1986); rational individual and group actions within a social structure (Coleman, 1990); social resources accessible through moving within and between networks (Lin, 2001a); and facets of civic organisations (Putnam, 1993).

Since Portes' (1998) work on social capital and ethnicity, studies linking social capital and migration have proliferated. They have confirmed the significant role of social capital in the initiation of migration and the outcome of settlement (Aguilera and Massey, 2003). Much of social capital scholarship distinguishes between bonding and bridging networks in gauging social integration (e.g., Putnam, 2000). Recent studies (Author 2, 2015; Ryan, 2011) have shown how social capital contributes to migrants' receiving support for settlement. However, social network dynamics are particularly complex in the context of Chinese overseas migration from mainland China (our focus in this article), because Chinese 'guanx/ networks are thought to operate in different ways to social capital networks. 
The term 'guanxl represents Chinese interpersonal relationships (Yang, 1994). Despite the simultaneous rise in both social capital and guanxi studies in recent years, engagement between the two literatures is rare, and the lack of comparison is still an important omission in the field of migration. Some studies proffer routine generalisations, seeing guanxi as a vague subset of social capital (Luo, 2000), or else assert that guanxi is a particularistic strongtie relationship (Hwang, 1987). The few studies that have tried to compare social capital and guanxi focus mostly on network structures or norms.

Structural comparisons typically suggest that guanxi is comprised of strong-tie, familyoriented networks (Fei, 1992). While Lin (2001b) notes that guanxi is characterised by its ability to access other social ties where useful resources are embedded-which makes it a similar concept to social capital-Huang and Aaltio's (2014) study of Chinese female managers' social networks finds that guanxi is limited in size, underscores strong-ties, and creates 'redundant' contacts.

Normative comparisons imply that Confucianism, obligations, and 'face' are more important for guanxi. Qi (2013) identifies guanxi as originating in the absence of law and practices of civil society, and investigates the differential trust dynamics to guanxi. There is no attention paid to the role of guanxi in fostering certain practices, such as civic activity and volunteering: a core component of the social capital literature.

The scant comparative literature suggests that guanxi largely consists of 'strong ties', while social capital is comprised of 'weak ties'; and that the former is mostly closed off from the latter on this basis, which creates potential problems for migration and integration. The critical weakness with this consensus, however, is that these studies focus on only one network facet rather than integrating these and other qualities in a comprehensive comparison of social capital and guanxi. The similarities and differences between guanxi and social 
capital are not yet clear and the consequences for Chinese migrants who try to mesh the two network types are not yet apparent.

This paper redresses this omission by critically reviewing the core literature in the social capital and guanxi fields, and contrasting what each says about norms, structures and practices in the context of migration.

\section{Method}

A scoping review of journal articles on the concept of social capital and guanxi was chosen in this study. To find the relevant journal articles, we used two research databases: Scopus and Web of Science (WoS). We first listed all keywords relevant to our study (Table 1). We also selected 'migration' as a keyword to examine the dynamics of social capital and guanxi in the context of migration. Next, we conducted a preliminary search on both Scopus and WoS in March 2019.

\section{[Table 1]}

The first step of this search was to identify literature on social capital and guanxi in the databases. In each instance, the search was limited to articles from 1999 to 2019, and restricted to key disciplinary areas such as 'social sciences', 'business, management and accounting', 'arts and humanities', etc.

We first did a search combining just the term 'social capital' with 'guanxi or renqing or mianzi or face'. We identified 590 documents in Scopus, and 392 articles in WoS.

We next restricted the search to articles that combined the term 'social capital' AND at least one of the other keywords related to social capital in Table 1 AND any of the keywords for guanxi. This Scopus search generated 161 hits while the WoS search generated 135 results. 
We then repeated our search combining just the term 'social capital' with 'guanxi or renqing or mianzi or face', but this time including the term 'migration'. This search on Scopus generated 27 hits, while the WoS search generated 23 results. Finally, we repeated our search of articles that combined the term 'social capital' AND at least one of the other keywords related to social capital AND any of the keywords for guanxi, AND this time also included 'migration'. This final search on Scopus generated three hits, while the WoS search generated nine results.

After we removed articles that repeated across the Scopus and WoS searches, we ended up with 230 articles from the 'social capital AND social capital-related term AND guanxl search, and 43 articles from the 'social capital AND guanxi AND migration' search. We next manually reviewed these articles' abstracts to ensure relevant literature featured, according to two criteria: (1) there was a frequent use of a combination of relevant key concepts; and (2) the abstract included both the social capital and guanxi concepts at a minimum. A total of 29 articles were selected for detailed review. From these, we identified relevant articles in the reference lists that were also included and subject to review. This brought the final total of reviewed articles to 38 .

Over half (22) of the reviewed articles were from the disciplinary area of business and management. Fourteen articles were from social science literature. Two articles were from arts and humanities. We noted that while conceptions of guanxi from business and management were somewhat distinct from those in the social sciences, with a stronger (and less critical) focus on the role of culture in networks (rather than other sociological factors, like class, education, gender, etc.), we nonetheless detected similarities that inform our theoretical framework, and we use sociological literature as well to round out the analysis.

We searched for four specific factors that we considered to be important for the article, comparing migrants' social capital and guanxi each on the basis of: (1) their normative 
underpinnings (2) their network structures (3) their network practices, and (4) the brokerage and resources utilised by each network.

\section{Competing norms}

\section{Ideology and cultural values}

The ideology of individualism underpins much of the social capital literature. People form institutions that reflect the importance of individual rights and responsibilities (Kim, 1994). The objective of social transactions is to maintain the balance between self and society, with great emphasis placed on gains from the interaction.

Chinese culture is relational and collectivist. Relational orientation has been used by several scholars to describe the characteristics of Chinese individuals (Ho, 1993; Yang, 1995). We understand relational culture to be one where individuals pay close, long-term attention to how they and others interrelate; or have a focus on maintaining harmony within a given social network. Collectivist orientation is a broader cultural concern, shown through collective adherence to society-wide interests typically taking precedence over individual interests (Ho, 1993). According to Barbalet (2016), guanxi, which involves reciprocal cultural obligations, face and favours, cannot be appreciated in terms of notions of individualism held by westerners, or people of western European descent. Chinese people construct their self-identities around their relational position and collectivist role in the society.

The differences in family structure are reflected in guanxi and social capital literatures. Whilst acknowledging a multiplicity of family forms in modern western contexts-singular, blended, extended family (Coontz, 2000)_most present-day western families still take a nuclear-family shape, prioritising the nuclear-family over multi-generational joint or extended-kinship families. By contrast, the more extended-kinship structure of traditional Chinese families produces more fluid boundaries and multiple responsibilities (Fei, 1992). 
This extended-kinship structure can be seen in the inter-generational family obligation provisions of the 1980 Marriage Law. For example, orphaned grandchildren have the duty to support their grandparents, and elder siblings are obliged to support their younger siblings if the parents are deceased (Barbalet, 2016).

Differences in family structures contribute to variations in network norms. Traditional scholars have defined guanxi as a relationship between people with a sense of obligation that arises out of family commitment (Fei, 1992; King, 1991). Confucianism values harmony as a key ingredient of human wellbeing and emphasises fulfilling the responsibilities of a given role in relationships that define Chinese society (King, 1991). Guanxi is therefore appreciated as an extension of family relations, and reflects the significance of fulfilling obligations within a longer-term orientation that maintains social harmony.

The important difference here is in the obligations each network affords. With guanx/s emphasis on filial piety, the self is an integral part of an extended family. There is an expectation that individuals subordinate their personal goals to those of the family, and by extension, society (Triandis, 1988). The extended family is not so central to social capital networks.

Extended-familly obligations have a more critical role within guanxi than social capital, which has significant implications for Chinese migrants. Migrants are likely to become overreliant on family guanxi and be unable to understand or mistake individualistic values. Such misapprehensions would negatively affect migrants' integration, by reinforcing their biases against westerners and forming weaker-ties with them. Similarly, and in reverse, westerners might be likely to mistake Chinese collectivist norms as conformist and homogenising, without recognising the orientation behind such norms towards achieving social harmony. 


\section{Ethics of reciprocity}

The norm of reciprocity regulates transactions of giving and returning information and resources within social capital networks. Portes (1998) distinguishes two types of reciprocity—particularised (direct return) and generalised (indirect return). Despite the direct or indirect return, the amount of the return should be roughly equivalent and contingent on the value of the benefit received (Zhang, 1998). As one's obligation can be discharged after the repayment, the requirement to interweave longer-term relationships through ties of obligation are lessened.

Guanxi has specific reciprocal principles, renqing. Scholars have offered diverse explanations about the meanings of renqing. 1) the norm of reciprocity/obligation (King, 1991); 2) friendship relations reserving close feeling within family (qinqing) (Lin, 2001b); 3) human feeling (Yan, 1996); 4) favours (Yang, 1995); 5) resources (Hwang, 1987). Although renqing and reciprocity share a common obligation of giving and returning, renqing has some Chinese characteristics: a long-term and other-orientation; a continuation of an obligation after the repayment; and asymmetric exchange principles (Zhang, 1998). Renqing also involves careful consideration of ritual, face and social harmony.

Although the constant exchange of resources encourages mutual help among Chinese migrants, this may lead to isolation from westerners due to a mutual misunderstanding of reciprocity dynamics, and the failure of westerners to return favours from Chinese migrants. Such favour-exchange is often regarded by westerners as an exercise in favouritism, nepotism and corruption (Yeung and Tung, 1996), rather than an act of network building.

\section{Face and facework}

The study of face in western contexts goes back to Goffman's (1967: 5) notion of face: "the positive social value a person effectively claims for himself by the line others assume he has taken during a particular contact". Such a definition emphasises the positive qualities of 
face. While Goffman (1963) notably addresses more negative perceptions of the self in the eyes of others in his work on stigma, he does not incorporate negative aspects into two discrete sets of face that can help explain the operation of Chinese social networks, and the concept has not been picked up by social capital scholars.

The dynamics of face have been essentially incorporated into the literature on guanxi. The concept of face in China is hierarchical and collective. It is a binary notion that involves two aspects: social face derived from one's social status and linked to one's abilities, economic status and social relationships, and moral face derived from one's moral character (Shi et al., 2011). Chinese face-typically representing one's social power, status, connections-is a basic instrument for allocating resources (Hwang, 1987). It is not only the prerequisite for people in guanxi to obtain privileges, but also an outcome of guanxi. Individuals can gain credibility and build good relationships by saving their own face and protecting others'. As Chinese relational and collectivist culture focuses on a higher degree of other-face, guanxi requires more recognition of protecting other-face. Although Goffman (1967) identifies face-saving techniques in western culture, there are few social capital studies that explicitly link face and social capital.

This has significant implications for Chinese migrants: there is stronger potential for making mistakes in bridging between two cultures. Chinese migrants are more clearly able to identify who is of higher and lower social status in a given situation (e.g., one's age, class, position in the power structure), and have clearer ideas of how one should behave and apply the appropriate face-strategies. As rules are more fluid and flexible in late modern western societies, westerners may be confused by the lack of clear rules in those situations, and often engage in activities that Chinese people interpret as losing face. Losing face in guanxi networks generates negative emotions (Qi, 2011), and may deteriorate relationships between migrants and westerners. 


\section{Trust}

Trust plays a prominent role in theorising about the importance of social capital in civil society (Cook, 2005). Trust reduces uncertainty and the potential risk embedded in investment in social capital through providing credentials to mobilise resources (Granovetter, 1973). Other authors claim that some forms of trust are emotional qualities based on norms rather than information and rational choice. Scholars such as Uslaner and Conley (2003) and Author 2 (2004) distinguish between these two types-generalised trust based on norms and particularised trust based on shared experience and accumulated information about the trustworthiness of the other-and tie them back to social capital. Bonding networks operate on highly particularised trust, while bridging networks operate on highly generalised trust, and both operate broadly in an interrelated system (Author 2, 2009; 2010).

Chinese trust dynamics reveal properties closer to particularised trust, based on information about other's trustworthiness. Since guanxi originated in the absence of institutionalized forms of assurance (Qi, 2013), the trust that characterises guanxi extends outwards from the family. As norms of generalised trust outside of family are poorly developed, individuals build up their xinyong (trustworthiness) through their transactions with others, most particularly in reciprocating favours (Luo, 2000). However, xinyong is not as strictly particularistic as it might be within a conventional bonding network. It is transferable between guanxi networks, and can be 'borrowed' in advance to build connections (Qi, 2013). One's xinyong can be vouched by an intermediary which constitutes a form of 'brokerage'.

We argue that guanxi operates through processes of particularised trust based on xinyong, rather than via norms of generalised trust that characterise Putnam's civil society and bridging capital, though the xinyong-based trust is distinct from western particularised trust in two ways. First, xinyong-based trust is closely related to one's face. Second, the 
transferability of guanxi through xinyong offers greater networking opportunities beyond the limitations of western particularised trust and bonding capital. Given that guanxi generally operates through xinyong-based trust, and introductions by intermediaries are often much more effective than 'self-initiated acquaintance' (Yang, 1994: 124), Chinese migrants may not be willing to embrace western generalised trust. This is a disadvantage of Chinese culture with respect to immigration and integration: migrants who do not embrace generalised trust rely more on their limited guanxi.

\section{Distinct network structures}

\section{Western organisational versus differential mode of association}

Before examining the structural elements of the two networks, it is important to consider the structure of the society in which they operate. In Western society, the common units are organisations formed by individuals. Most such organisations have clear boundaries to distinguish members from non-members. All members in an organisation are equivalent in terms of the membership criteria, and personal relationships are then developed through this structure (Fei, 1992).

In Chinese society, the basic structure is a 'differential mode of association', whereby "social relationships spread out gradually from individual to individual, resulting in an accumulation of personal connections" (Fei, 1992: 43). In such a pattern, one can spread their social influence across everyone else's overlapping and egocentric networks at different times and places (Fei, 1992). As guanxi can be extended to embrace countless numbers of people, Chinese people employ multiple standards to treat people in different circles. These circles are often based on tie-strength between guanxi participants that changes from situation to situation.

To integrate structural elements of guanxi with social capital theory, we suggest dividing guanxi into 'core' and 'periphery' aspects, which form a useful contrast-but not an exact 
equivalent-with 'bonding' and 'bridging' capital. We propose that the core of a guanxi revolves around the centred-ego of guanxi circles, which includes two types of ties, family ties and broader familiar ties. Familiar ties (e.g. relatives, classmates, and close friends) are usually considered strong ties, as they not only involve reciprocal exchanges but also 'emotional support' (Luo et al., 2017: 73). Peripheral guanxi includes ties that are more distant from the centred-ego, generally including acquaintances and outsiders/strangers (e.g. supervisor-subordinate, salesman-customer). Such ties are more fluid, and more likely to be intentionally (and instrumentally) formed with limited liability in social-exchanges (Luo and Cheng, 2015). The tie strength between guanxi participants is not fixed; it is determined by their needs and changes according to the situation. For example, an employee can build up a previously weak tie into a strong tie with his/her superior by frequent social interactions outside working hours, as he/she needs mentorship, strategic information, and social support (Bian, 2019). The core and the periphery based on tie-strength are therefore fluid, as one may move peripheral ties out and put outsiders into the inner group, and also move trustworthy peripheral ties into the core (Luo and Cheng, 2015).

Chinese people employ renqing as a control mechanism to channel network activities with reduced risks and maximised benefits (Guo and Miller, 2010). Chinese migrants are afforded higher levels of support from core guanxi, and have greater flexibility in navigating opportunities that arise from developing peripheral guanxi. They can find the stricter boundaries between western acquaintances/strangers and close friends/family somewhat alienating, much as westerners are more uncomfortable with the fluidity between core and peripheral guanxi.

\section{Tie multiplexity}

Interpersonal ties can be distinguished based on their expressive/instrumental function. Instrumental ties arise in the course of work-role performance that facilitate the transfer of 
physical, informational, or financial resources, and expressive ties provide friendship and social support (Manev and Stevenson, 2001). This distinction manifests in different ways for social capital and guanxi. Bonding networks oriented to kin are more likely to be supportive and emotionally expressive, while those oriented to self or closed-group concerns, such as capital accumulation (Bourdieu, 1986) are more instrumental. Similarly, bridging networks can seek purposive, goal-oriented, and instrumental engagement with the public, or involve emotional attachments oriented to achieving altruistic social goals. However, whilst each motivation is possible within either network, a multiplex interplay between them is less visible than with guanxi.

Expressive and instrumental functions can manifest in the development of matching (expressive and instrumental) guanxi ties, and also in ties that mix both functions. The expressive tie occurs mostly among members of core groups, while the instrumental tie occurs mostly among members of peripheral groups. Mixed ties largely occur among familiar ties, and are both instrumental and affection-based (Guo and Miller, 2010). There is significant crossover evident in these guanxi ties, in that expressive ties with a sentimental nature attached to gift exchange can bring instrumental possibilities, while the instrumental ties can also bring social connections and new possibilities for emotional support. In China, people are adept in utilising such ties to obtain support/resources. Much of the interplay between these ties accords to different rules. People generally employ the need rule among expressive ties, the equity rule among instrumental ties, and renqing rule among mixed ties (Hwang, 1987).

This has important implications for migrants in the potential for cultural confusion over tie formation and usage, in that actions can be seen by non-Chinese people as instrumental when they should be expressive, and vice versa. Guanxi ties are a multiplex mix of norms encompassing exchange, renqing, and face, and many Chinese entrepreneurs run business 
with friends, relatives, or former classmates in accordance with these norms. Chinese migrants might form and use mixed ties with westerners when they should be employing instrumental or expressive ties in prescriptive ways, resulting in loss of face.

\section{Network size, density and diversity}

Both guanxi and social capital can consist of large networks that operate on the scale of communities and nations. Social capital—at least when conceived in its bridging variantconsists of organisations with a largely unambiguous system of membership that clarifies rights and duties (Fei, 1992). Bonding networks such as families are generally smaller, illustrated in Marsden's (1987) finding that American social networks are small and kincentred.

Guanxi networks are variable in size. Core guanxi ranges from small- to medium-scale, while the peripheral guanxi is often large and can expand indefinitely (Guo and Miller, 2010). One's guanxi networks are constantly evolving at the peripheral edges, and the boundaries are quite fluid. The normative mechanisms identified above - the relational and collectivist culture, long-term extended-family, transferable trust and the motivation of enhancing one's face-also contribute to the unboundedness of guanxi. There is no limitation to guanxi size in the move from core to periphery, since it depends on the ability of the ego to bond with others. This is revealed in Blau et al.'s (1991) study that the size of Chinese discussion networks is larger than American discussion networks.

Network density refers to the degree to which all members in a network are interlinked with each other (Burt, 2000). Both guanxi and social capital can consist of high-density and low-density networks. The density in bonding networks such as families is generally high. Bridging networks, by contrast, are less dense.

Guanxi ranges from low-density to high-density. The core guanxi generally ranges from medium-density to high-density, while the density of peripheral guanxi is often low. Blau et 
al. (1991) find that the density of Chinese discussion networks is lower than American discussion networks, as Chinese have fewer family members and more co-workers in their discussion networks than Americans. Yet, the density of Chinese networks has been revealed higher than that of American networks in some studies (e.g., Peng, 2004; Chua and Morris, 2006).

Network diversity is another pertinent structural element. A high degree of homogeneity in networks enables stronger sanctioning capacity, stronger trust and shared norms (Coleman, 1990). Heterogeneous networks are characterised by various network members with different characteristics and can better mobilise resources (Lin, 2001a). Bonding networks are largely homogeneous, while bridging networks are often heterogeneous. Although Blau et al. (1991) identify guanxi networks as being less heterogeneous, their study focuses on the core guanxi and neglects the peripheral guanxi. As guanxi networks are dynamic and evolving, with permeable boundaries in the sense that outsiders (in terms of age, gender, or class) can join guanxi networks through intermediaries, Bian (2001) argues that the 'snapshot in time' measures of network heterogeneity, such as the name generator method in Blau et al.'s study, are less accurate in the Chinese context because of this dynamic quality, of change and movement between core and periphery over time. Bian and Zhang (2014) contend that guanxi networks survive with a certain degree of resource non-redundancy between guanxi participants. We argue that guanxi requires great heterogeneity to be valuable-largely at the periphery-as a certain level of resource non-redundancy maintains a guanxi-tie and network. This highlights the need for higher levels of heterogeneous contacts at the periphery, which accords with Bian's (2001) findings that network diversity in acquaintance guanxi is greater than amongst family and friend guanxi.

The ways in which migrants build and use networks are shaped by network structure, which determines how resources are mobilised. Guanxi has particularistic qualities in size, 
density and diversity that make it more fluid. We suggest that guanxi is like bonding capital, but with some bridging tendencies. Such arrangements can generate different network practices amongst Chinese migrants.

\section{Comparing practices}

It is important to note the practices that characterise networks (Author 2, 2004; 2010). While many studies focus on the passive membership and idealised values data, social capital is also comprised of time-related practices such as volunteering and active memberships (Author 2, 2004).

The tradition of social capital research stems largely from interest in the 'civic mindedness' of broad social communities, with Putnam (1993) demonstrating that a successful accumulation of social capital is closely associated with a high level of political integration. Putnam (2000) attributes a decline of social capital in the United States since 1950 to the reduction of civic engagement in organisations, volunteering, and protest. Within Putnam's theory, social capital is broadly seen as a western approach to understanding how social networks promote civic society. As social capital organisations are formed with clear, often formal boundaries and operate on highly generalised trust, people are more inclined to participate in civic activities because the connectedness of memberships can bring benefits (Putnam, 1993). Social trust and information transfer are enhanced when people participate in a range of voluntary organisations that encourage them to socialise outside their immediate kin circles (Putnam, 1993). Another motivation towards civic activity is altruistic and community-minded activism, in that volunteering, and the building and using of bridging social capital, are often oriented towards achieving a common social goal or democratic government (Putnam, 2000). An important element to Putnam's (2000) social capital approach is in the distinction between bonding and bridging social capital groups, with the former conveying advantages to closed groups and promoting limited volunteering, and the 
latter spreading opportunities more broadly across communities and promoting civic volunteering (Author 2, 2004).

Given that guanxi networks are not formed with clear boundaries nor oriented towards promoting civic organisation, they theoretically exhibit low levels of 'civicness'. Organised protest has traditionally been discouraged within Mainland China, under the stated ideal that 'excessive' emphasis on individual rights disrupts the Confucian sense of social harmony. According to the distribution of societies in terms of associational membership and social trust in the 2001 Wave of the World values survey, China, has relatively low associational membership (Norris and Inglehart, 2006). Yang (1994: 258) explains one historical derivation behind this, in noting that: "after the Revolution, any independent groups that did exist were either disbanded or gathered into the folds of state administration...it is still very difficult to form voluntary associations in China". We argue that guanxi is predominantly used within mainland China to acquire resources that help advance and connect individuals and families, and build a harmonious society.

We conclude that weak ties in social capital are not only more beneficial for acquiring non-redundant resources, but also for maintaining civic/voluntary associations, whereas weak ties in guanxi may not contribute much to widespread civic participation. Consequently, Chinese migrants might have difficulty adjusting from the limited availability of civic engagement options to practices of widespread and open civic participation. This is a negative quality of guanxi networks impeding Chinese migrants' integration: there is a potential for Chinese migrants to become socially isolated in their host societies.

\section{Different mobilisations}

We now examine how resources are mobilised differently according to varing structural properties, which is vital to understand how strong and weak ties theoretically work in Western and Chinese contexts. 


\section{Network tie strength}

Both guanxi and social capital have variations consisting of strong and weak ties. Bonding capital is typically constituted by strong ties and regulated by reciprocity norms, highly particularised trust, and mutual obligations, enabling members to be close to sources of information (Author 2, 2009; 2010). Bridging capital is constituted by weak ties (Granovetter, 1973) and regulated by highly generalised trust (Author 2, 2009; 2010), allowing individuals to be linked to diverse connections, non-redundant information/resources unavailable in their own social networks (Marsden, 1982). Numerous studies (Patacchini and Zenou, 2012; Ryan, 2011) link weak ties to the various forms of support associated with migrant social integration.

Core guanxi normally consists of strong ties. Guanxi resources are more highly embedded in pseudo-family ties than in 'other types of non-kin ties' (Bian, 2001: 292). Chinese people tend to rely heavily on their close relations instead of weak ties. Based on 1988 survey data, Bian (1997) contends that people tend to seek jobs through strong-ties in urban China. This finding is supported by Zang (2003) who finds that job seekers whose fathers are cadres or professionals are more likely to receive job information or obtain jobs from guanxi networks in the post-1988 period. However, peripheral guanxi is also important in some situations in China. Kinship bonds of familiarity can be weakened by distance away from urban areas (Yang, 1994), and favour seekers who are indirectly connected with their helpers through intermediaries are more likely to receive better jobs (Bian, 1997). In their cases, peripheral guanxi consists of weak ties and tends to be more effective for accessing better resources.

We conclude that while guanxi shares similarities with 'closed' bonding social capital networks, it also has a peripheral fluidity that grants it bridging and brokerage qualities. Previous studies have found that weak-tie networks of infrequent interaction and low 
intimacy are more widely used to acquire information about job openings in western countries (Granovetter, 1973) and are more useful than strong-tie networks, while strong ties are more effective for Chinese people to acquire state or high-level organisational positions in China (Bian, 1997). Chinese migrants have distinct preferences for using specific ties for building and using networks. This leads them to rely principally upon strong ties, which might cause social disconnection and alienation from host societies (Author 2, 2015).

\section{Closure and brokerage}

Network closure refers to a strongly interconnected network whereby "everyone is connected such that no one can escape the notice of others" (Burt, 2000: 351). A bonding network is largely closed, which enables members to be close to sources of information, strengthen trust, and undergird reciprocity (Putnam, 2000). Nevertheless, an excessively bonded network may exclude outsiders from positions and opportunities (Portes, 1998). Acts of brokerage-a process "by which intermediary actors facilitate transactions between other actors lacking access to or trust in one another" (Marsden, 1982: 202)—can help overcome closed networks in western contexts by occupying an intermediate position where one can influence the flow of information across bridging networks (Burt, 2000).

Although guanxi exhibits properties of closure via xinyong, face and renging to undergird reciprocity and mobilise solidarity, the transferable quality of xinyong insures that guanxi networks remain relatively open. Chinese people also employ renqing as a mechanism to drive brokerage and channel network activities with reduced risks (Guo and Miller, 2010).

We conclude that strong ties in guanxi are better for drawing on valuable resources in Chinese contexts-through the dynamics of renqing and face-but such strong guanxi ties are rarely transformed into western social capital, even by acts of brokerage. As strong guanxi ties require mutually accepted cultural understandings of renqing and face, Chinese migrants may have difficulties in building strong ties with westerners. 


\section{Discussion}

Our literature review reveals key similarities and several fundamental differences between social capital and guanxi. in terms of face, renqing and civics. While each network type is characterised by norms of trust and reciprocity, the social integration basis that typifies social capital incorporates individual and civic responsibilities. Guanxi networks are underpinned by strong and recognisable dynamics of face and renqing and are infused with Confucianism which emphasises family-commitment and social harmony. Both networks require trust of some form to deal with uncertainty. Bonding networks operate on highly particularised trust, while bridging networks operate on highly generalised trust. Guanxi networks operate through processes of particularised trust based on xinyong. These similarities and differences are summarised in Table 2.

\section{[Table 2]}

Normative differences create difficulties for Chinese migrants both in building new social networks in western contexts, and in linking existing guanxi connections with these networks. We have noted that Chinese migrants might form strong biases against westerners, form weaker ties, and not be willing to risk engaging more widely by relying on norms of generalised trust. We suggest that more cultural education programs in areas with exposure to Chinese people should be made available. We will give a more detailed recommendation in our conclusion.

Guanxi has some universal structural elements that also exist in social capital. It shares similarities with closed bonding networks. However, the core/periphery aspects grant it bridging qualities as well, and render it more open, heterogeneous, and fluid than closed bonding networks (Table 3). Guanxi operates in the unique cultural framework of China and reveals exceptional properties. Differential dynamics of xinyong, face and renging enable 
guanxi to operate across many groups within China, and also amongst the Chinese international diaspora. Guanxi can break the boundaries of existing network circles, and bridge from core to periphery-and across many peripheries-more harmoniously than can be achieved through many bridging networks. The flexibility of movement between core and peripheral guanxi also implies a potential absence of the 'dark-side' of bonding network obligations as identified by Portes (1998). Even so, guanxi still entails obligations to extended family and Confucianism, which are absent from social capital and can disadvantage those with low status and face and can stifle civic participation.

\section{[Table 3]}

Differences in network structures can create difficulties for overseas Chinese. Chinese migrants have distinct preferences for ties, tending to rely upon strong ties and eschew weak ties. They also experience cultural confusion over tie usage and formation; and are not used to engaging in broad civic activities. These repercussions put migrants in a danger of becoming socially isolated and lacking economic and social support. We suggest that greater efforts by governments and NGOs are needed to facilitate active participation by Chinese migrants in civic activities. They will also be discussed further in our conclusion.

Chinese people tend to rely heavily on their strong-ties to acquire jobs instead of weak ties, since strong ties are more advantageous in exerting influence to obtain favours rather than simply gathering employment information (Bian, 1997). As face represents the social power, status, and resources an individual has, it determines their influence. The requirements of face are more important in guanxi. As guanxi uses both strong and weak ties to build connections, we argue that the strong ties require mutually accepted understandings of face to work effectively, which limit their cross-over and transformation into western social capital. 
When peripheral guanxi ties are bridged through intermediaries, they can work effectively to obtain distant or better resources.

Although social capital and guanxi are similar in terms of their potential for accessing other social ties where useful economic resources are embedded, weak ties in social capital networks are more strongly emphasised in western literature, as they can offer non-redundant information and resources, and are used to start civic enterprise and voluntary associations. As social capital networks are formed with formal boundaries and highly generalised trust, people are more inclined to participate in civic activities, and to achieve a common social goal or hold a democratic government. By contrast, guanxi has a low level of 'civicness'; it is used more to acquire resources, connect individuals, and promote social harmony.

\section{Conclusion}

Differences and misunderstandings in norms, structures, and practices create difficulties for the integration of overseas Chinese. We have noted that Chinese migrants may have difficulties building strong guanxi ties with westerners. The results are particularly important for the Chinese diaspora in western civic societies.

First, the face-based network makes strong-ties more influential in terms of solving problems, which has been extended from family to social life, and on to labour-market and business activities. However, as the dynamics of face have been largely absent from social capital scholarship and face rules are more fluid and flexible in late modern western societies, the loss of face generates negative emotions, and may deteriorate relationships between migrants and westerners in the long run. Westerners encounter cultural confusion over norms of face and renqing. We argue that cultural education programs in areas where there are high concentration of Chinese people-universities, certain business enviroments, tourist sites, and certain residential neighbourhoods-could be effective at connecting guanxi and western social capital. 
Second, while some research suggests that weak-tie networks of infrequent interaction and low intimacy are more widely used in job-seeking to acquire information in western countries (Granovetter, 1973), Chinese people tend to use strong-ties to acquire jobs, particularly when seeking employment within large, closed, state-run institutions (Bian, 1997). Our study found that Chinese migrants tend to heavily rely upon strong ties, using weak ties much less, which may put them at risk of isolation in their host countries (Author 2 , 2015). We contend that Chinese migrants dependent upon strong-ties exclusively with groups of co-ethnics can be socially disadvantaged, as this dense network may exacerbate competition, rivalry, exploitation, cheating and distrust (Ryan et al., 2008). Migrants not only face the personal adjustment challenges, but also suffer consequent emotional problems, such as anxiety, loneliness, and uncertainty about their situations. We recommend that more social support be made available for Chinese migrants in terms of career support, cultural programs and language programs, to help them settle into their host countries and counter alienation, acculturative stress and anxiety.

Another important challenge for Chinese migrants is civic engagement; they are less inclined to join civic/voluntary associations than westerners. We suggest that greater efforts by governments and NGOs in the host countries are needed to facilitate active participation by Chinese migrants in voluntary associations and community activities. For example, the Australian government provides a variety of settlement services and integration activities to newly arrived migrants. Yet, the majority of settlement services are only available to humanitarian entrants who make up only a small part of the total number of migrants coming to Australia (Spinks, 2009). For other types of migrants such as skilled migrants, family visa holders and international students, there is no alternative program or service provided by the Australian Government to support them in building connections with the broader community. Thus, we suggest that the Australian Government explore options to enhance community 
connectedness for other types of migrants. We also suggest that NGOs founded by Chinese communities should initiate more cultural activities and programs outwardly for non-Chinese people in the host countries.

As the purpose of our research is primarily to identify the issues faced by Chinese migrants in general, a detailed analysis of all the possibilities is beyond our scope. Our findings may not be applicable to all types of Chinese migrants; further research is needed to examine differences between specific groups of migrants. We note the different impacts of guanxi for Chinese male and female migrants: female migrants are less active than male migrants in a wider range of public social activities. Influenced by the deep-rooted Confucian principles, Chinese society's role expectation for today's women includes providing care for the family, being dutiful wives and devoted mothers, playing subordinate roles in the family and in society (Xu and Li, 2015). This role expectation for women shapes their attitudes toward network practices and community engagement. Xu and Li's study (2015) find that urban Chinese women evaluate the practice of guanximore negatively than men because they consider that practising guanxi requires crude instrumentalism and aggressive tactics; these women report avoiding frequent participation in social events, and the belief that women who are good at practicing guanxi may develop negative reputations in broader society. We argue that these social attitudes may contribute to female Chinese migrants' detachment from community in their host countries. We suggest that more easily-accessed practical support for female migrants including childcare and employment services, training program, hotline and counseling service are needed, with more programs designed to increase active participation by female migrants in sport, recreation, voluntary and other community activities.

\section{Bibliography}

Author 2. (2004) Blinded for peer review.

Author 2. (2009) Blinded for peer review. 
Author 2. (2010) Blinded for peer review.

Author 2. (2015) Blinded for peer review.

Aguilera, M.B. and D.S. Massey (2003) 'Social Capital and the Wages of Mexican Migrants: New Hypotheses and Tests', Social Forces 82(2): 671-701.

Barbalet, J. (2016) 'Chinese individualization, revisited', Journal of Sociology 52(1): 9-23.

Bian, Y. (1997) 'Bring Strong Ties Back in: Indirect Ties, Network Bridge, and Job Searches in China', American Sociological Review 62(3): 366-85.

Bian, Y. (2001) 'Guanxi Capital and Social Eating in Chinese Cities: Theoretical Models and Empirical Analyses', pp. 275-95 in N. Lin, K. Cook and R. Burt (eds) Social Capital Theory and Research. New Jersey: Transaction Publishers.

Bian, Y. and L. Zhang (2014) 'Corporate social capital in Chinese guanxi culture', Research in the Sociology of Organizations 40: 417-39.

Bian, Y. (2019) 'Guanxi and Organizational Development', pp. 128-67 in Guanxi: How China works. Cambridge: Polity Press.

Blau, P.M., D. Ruan and M. Ardelt (1991) 'Interpersonal choice and networks', Social Forces 69(4): 1037-62.

Bourdieu, P. (1986) 'The Forms of Capital', pp. 241-58 in J. Richardson (ed.) Handbook of Theory and Research for the Sociology of Education. New York: Greenwood Press.

Burt, R.S. (2000) 'The Network Structure of Social Capital', Research in Organizational Behaviour 22: 345-423.

Chua, R. and M. Morris (2006) 'Dynamics of Trust in Guanxi Networks', pp. 95-113 in Y. Chen (ed.) National culture and groups. Amsterdam: Elsevier.

Coleman, J. (1990) Foundations of Social Theory. Cambridge, MA: Harvard University Press. 
Cook, K.S. (2005) 'Networks, Norms, and Trust: The Social Psychology of Social Capital 2004 Cooley Mead Award Address', Social Psychology Quarterly 68(1): 4-14.

Coontz, S. (2000) 'Historical Perspectives on Family Studies', Journal of Marriage and the Family 62: 283-97.

Fei, X. (1992) From the Soil: the Foundations of Chinese Society. Berkeley: University of California Press.

Goffman, E. (1963) Stigma: Notes on the Management of Spoiled Identity. Englewood Cliffs, N.J.: Prentice-Hall.

Goffman, E. (1967) 'On face-work: an analysis of ritual elements in social interaction', pp. pp5-45 in Interaction Ritual: Essays on Face-to-Face Behavior. New York: Doubleday.

Granovetter, M. (1973) 'The Strength of Weak Ties', American Journal of Sociology 78(6): 1360-80.

Guo, C. and J.K. Miller (2010) 'Guanxi Dynamics and Entrepreneurial Firm Creation and Development in China', Management and Organization Review 6(2): 267-91.

Ho, D.Y.F. (1993) 'Relational orientation in Asian social psychology', in U. Kim and J.W. Berry (eds) Indigenous psychologies: Research and experience in cultural context. Newbury Park, CA: Sage Publications.

Huang, J. and I. Aaltio (2014) 'Guanxi and social capital: Networking among women managers in China and Finland', International Journal of Intercultural Relations 39: 2239.

Hwang, K.-k. (1987) 'Face and Favor: The Chinese Power Game', The American Journal of Sociology 92(4): 944-74.

Kim, U. (1994) 'Individualism and collectivism: Conceptual clarification and elaboration', pp. 1-16 in U. Kim, H.C. Triandis, C. Kagitcibasi, S.-C. Choi and G. Yoon (eds) 
Individualism and collectivism: Theory, method, and applications. Thousand Oaks: CA: Sage.

King, A. (1991) 'Kuan-hsi and Network Building: A Sociological Interpretation', Daedalus 120(2): 63-84.

Lin, N. (2001a) Social Capital: A Theory of Social Structure and Action. Cambridge: Cambridge University Press.

Lin, N. (2001b) 'Guanxi: A Conceptual Analysis', pp. 153-66 in A.Y. So, N. Lin and D. Poston (eds) The Chinese triangle of Mainland China, Taiwan, and Hong Kong: comparative institutional analyses. Westport: Greenwood Press.

Luo, J.-D. and M.-Y. Cheng (2015) 'Guanxi Circle's Effect on Organizational Trust: Bringing Power and Vertical Social Exchanges Into Intraorganizational Network Analysis', American Behavioral Scientist 59(8): 1024-37.

Luo, J.-D., X. Han, R. Burt, C. Zhou, M.-Y. Cheng and X. Fu (2017) 'Chapter 4 Measurement of Guanxi Circles: Using Qualitative Study to Modify Quantitative Measurement', in X. Fu, J.-D. Luo and M. Boos (eds) Social Network Analysis: Interdisciplinary Approaches and Case Studies. New York: CRC Press.

Luo, Y. (2000) Guanxi and Business. Singapore: World Scientific

Manev, I. and W. Stevenson (2001) 'Nationality, Cultural Distance, and Expatriate Status: Effects on the Managerial Network in a Multinational Enterprise', Journal of International Business Studies 32(2): 285-303.

Marsden, P.V. (1982) 'Brokerage Behavior in Restricted Exchange Networks', pp. 201-18 in P. Marsden and N. Lin (eds) Social Structure and Network Analysis. Beverly Hills: CA: Sage.

Marsden, P.V. (1987) 'Core Discussion Networks of Americans', American Sociological Review 52(1): 122-31. 
Norris, P. and R. Inglehart (2006) 'Gendering social capital: Bowling in women's leagues?', pp. 73-98 in B.O'Neill and E. Gidengil (eds) Gender and Social Capital. New York: Routledge.

OECD (2001) The Wellbeing of Nations: The Role of Human and Social Capital, Education and Skills. Paris: OECD Centre for Educational Research and Innovation.

Patacchini, E. and Y. Zenou (2012) 'Ethnic networks and employment outcomes', Regional Science and Urban Economics 42(6): 938-49.

Peng, Y. (2004) 'Kinship Networks and Entrepreneurs in China's Transitional Economy', American Journal of Sociology 109(5): 1045-74.

Portes, A. (1998) 'Social Capital: Its Origins and Applications in Modern Sociology', Review of Sociology 24: 1-24.

Putnam, R. (1993) Making democracy work: Civic traditions in modern Italy. Princeton, NJ: Princeton University Press.

Putnam, R. (2000) Bowling Alone: The Collapse and Revival of American Community. New York: Simon \& Schuster Paperbacks.

Qi, X. (2011) 'Face: A Chinese concept in a global sociology', Journal of Sociology 47(3): 279-95.

Qi, X. (2013) 'Guanxi, social capital theory and beyond: toward a globalized social science', The British Journal of Sociology 64(2): 308-24.

Ryan, L., R. Sales, M. Tilki and B. Siara (2008) 'Social Networks, Social Support and Social Capital: The Experiences of Recent Polish Migrants in London', Sociology 42(4): 67290.

Ryan, L. (2011) 'Migrants' social networks and weak ties: accessing resources and constructing relationships post-migration', The Sociological Review 59(4): 707-24. 
Shi, Z., L. Wen, Z. Huang and J. Ye (2011) 'An empirical study of face need effects on advertising of luxury', Innovative Marketing 7(3): 40-50.

Spinks, H. (2009) Australia's sett/ment services for migrants and refugees. Parliament of Australia.

Triandis, H. (1988) 'Collectivism V. Individualsim: A Reconceptualisation of a Basic Concept in Cross-cultural Social Psychology', pp. 60-95 in C. Bagley and G.K. Verma (eds) Cross-Cultural Studies of Personality, Attitudes and Cognition. London: Palgrave Macmillan.

Uslaner, E. and R. Conley (2003) 'Civic Engagement and Particularized Trust: The Ties That Bind People to Their Ethnic Communities', American Politics Research 31(4): 331-60.

Xu, K. and Y. Li (2015) 'Exploring guanxi from a gender perspective: urban Chinese women's practices of guanxi', Gender, Place \& Culture: A Journal of Feminist Geography.

Yan, Y. (1996) The Flow of Gifts: Reciprocity and Social Networks in a Chinese Village. Stanford: Stanford University Press.

Yang, K.S. (1995) 'Chinese social orientation: An integrative analysis', in T.Y. Lin, W.S. Tseng and E.K. Yeh (eds) Chinese societies and mental health. Hong Kong: Oxford University Press.

Yang, M.M. (1994) Gifts Favors and Banquets: The Art of Social Relationships in China. Ithaca: Cornell University Press.

Yeung, I.Y.M. and R.L. Tung (1996) 'Achieving business success in Confucian societies: the importance of guanxi (connections)', Organizational Dynamics. 54-65.

Zang, X. (2003) 'Network resources and job search in urban China', Journal of Sociology 39(2): 115-29. 
Zhang, Z. (1998) The role of Guanxi and Renqing in Chinese reward allocation University of Hong Kong. 
Table 1. List of keywords selected for literature review research.

\begin{tabular}{|c|c|c|c|c|}
\hline Keywords for social capital & & $\begin{array}{l}\text { Keywords for } \\
\text { guanxi }\end{array}$ & & $\begin{array}{l}\text { Keyword for } \\
\text { migration }\end{array}$ \\
\hline $\begin{array}{l}\text { Social capital, bonding, bridging, } \\
\text { trust, reciprocity, favour, } \\
\text { volunteering, civic participation }\end{array}$ & AND & $\begin{array}{l}\text { Guanxi, } \\
\text { renqing, face, } \\
\text { mianzi }\end{array}$ & AND & Migration \\
\hline
\end{tabular}


1

2

3

5

6

7

8

9

10

Table 2. Comparison of social capital and 'guanxi': network norms.

\begin{tabular}{|c|c|c|c|}
\hline \multirow[t]{2}{*}{ Network norms } & \multicolumn{2}{|c|}{ Social capital } & \multirow{2}{*}{$\begin{array}{c}\text { Guanxi } \\
\text { Core and periphery }\end{array}$} \\
\hline & Bonding & Bridging & \\
\hline Social & Individualism/ & Individualism/civic & Collectivism/Confucianism/ \\
\hline integration & Western family/ & & extended-family \\
\hline bases & civic & & \\
\hline Reciprocity & Specific/direct & Generalised/indirect & $\begin{array}{l}\text { Renqing-long-term/other- } \\
\text { orientation }\end{array}$ \\
\hline $\begin{array}{l}\text { Generalised } \\
\text { trust }\end{array}$ & Low & High & Low \\
\hline $\begin{array}{l}\text { Particularised } \\
\text { trust }\end{array}$ & High & Low & High \\
\hline $\begin{array}{l}\text { Face- } \\
\text { understandings }\end{array}$ & $\begin{array}{l}\text { Unitary notion } \\
\text { that indicates } \\
\text { self-images }\end{array}$ & $\begin{array}{l}\text { Unitary notion that } \\
\text { indicates self-images }\end{array}$ & $\begin{array}{l}\text { Binary notion that represents } \\
\text { self-images consisting of } \\
\text { social and moral aspects }\end{array}$ \\
\hline Face-impact & Low & Low & High \\
\hline
\end{tabular}


Table 3. Comparison of social capital and 'guanxi: network structure.

\begin{tabular}{|c|c|c|c|c|}
\hline \multirow{2}{*}{$\begin{array}{l}\text { Network } \\
\text { structure }\end{array}$} & \multicolumn{2}{|c|}{ Social capital } & \multicolumn{2}{|l|}{ Guanxi } \\
\hline & Bonding & Bridging & Core & Periphery \\
\hline Society & Organisational & Organisational & Differential & Differential \\
\hline \multirow[t]{2}{*}{ structure } & mode of & mode of & mode of & mode of \\
\hline & association & association & association & association \\
\hline Tie- & Expressive/ & Expressive/ & From expressive & From mixed to \\
\hline multiplicity & instrumental & instrumental & to mixed & instrumental \\
\hline Size & Small & Large & $\begin{array}{l}\text { From small to } \\
\text { medium }\end{array}$ & Large \\
\hline Density & High & Low & From medium to & Low \\
\hline Diversity & Homogeneous & Heterogeneous & Relatively & Heterogeneous \\
\hline Tie strength & Strong & Weak & Strong & Weak \\
\hline Closure & High & Low & Medium & High \\
\hline Brokerage & Low & High & High & High \\
\hline
\end{tabular}

